\title{
School Readiness in Weekly Iron Folic Acid Supplementation Program in Urban Area, West Java, Indonesia
}

\author{
Apriningsih *1, Siti Madanijah², Cesilia eti Dwiriani², Risatianti Kolopaking ${ }^{3}$, Yessi Crosita ${ }^{3}$
}

\begin{abstract}
Background: School based weekly iron and folic acid supplementation (WIFAS) program was aimed to decrease anemia prevalence and improve the adherence to consume iron tablet. Limited information on the school perspective and their readiness to implement the program.

Objectives: To analyze program guidelines, stakeholders' perspective and school readiness to implement the program which will help evaluate and improve adherence to WIFAS.

Methods: Study population are stakeholder and school community of WIFAS program in Kota Depok. Purposive sampling technic were applied to select respondent .Using cross sectional design with mixed method approach to utilize social ecological model and community readiness model. Qualitative data were analyzed using thematic analysis. Bivariate analysis presented the correlation between school characteristic, school's knowledge, school 's attitude, school readiness with WIFAS implementation program score. Multivariate analysis presented regression analysis of WIFAS program implementation Results: Most of schools received awareness campaign regarding the program, only $38,9 \%$ have conducted a drinking together weekly, only $27.8 \%$ recorded their students' adherence. The average score for the school readiness was 3.36 (SD \pm 0.82 ), the school was in the vague awareness stage. There was a correlation between the score of school's knowledge, attitude toward WIFAS program, City Health Authority and Education Regional Office 's support score, the total score of the school readiness, got socialization with implementation of WIFAS $(r=0.35, r=0.2, r=0.49, r=0.21, r=0.66, r=0.43, p$ value $<0.005$ ). The strongest correlation with implementation of WIFAS was the school readiness total score, received socialization and score school's knowledge on WIFAS ( $p$ value $<0.005$ ) and City health Authority and Education regional office's support score for WIFAS program as covariant $(p>0.05)$.

Conclusions: School readiness is important factor of community and environment which contribute to behavior change. School realize that anemia and schoolgirl adherence to consume WIFAS had to solved but did not know how and assume outside parties can help solve the problem. The City Health Authority and Education Regional Office is expected to help improve the school readiness to implement the program.
\end{abstract}

Keywords: anemia, female adolescent, adherence, iron folic acid supplementation, school readiness

\author{
*Correspondence: \\ Apriningsih \\ apriningsih@upnvj.ac.id \\ ${ }^{1}$ Prodi Kesehatan Masyarakat, Universitas Pembangunan Nasional Veteran Jakarta. Kampus FIKES UPNVJ Limo Raya Depok \\ Jawa Barat \\ 2Departmen Gizi Masyarakat, Institut Pertanian Bogor. Dramaga Bogor Jawa Barat \\ ${ }^{3}$ Fakultas Psikologi, UIN Syarif Hidayatulloh Jakarta. Kampus II UIN Ciputat, Tangerang Selatan, Banten
}

\section{INTRODUCTION}

Anemia is one of the global health issues with substantial economic burden. The World Health Organization (WHO) estimates there are around two billion people suffered from anemia and half can be treated with iron. Adolescent girls aged $10-19$ years is one of the susceptible group to iron deficiency. ${ }^{1}$ Indonesian Basic Health Research (Riskesdas) in 2018 reported the national prevalence of anemia in adolescents female age group was 48.9. ${ }^{2}$ Smaller research in various regions in Indonesia however showed staggering high prevalence of anemia among adolescent girls ranging from ranging from $32.4 \%-61 \%$. ${ }^{3}$ Anemia among adolescent girls does not only affecting current academic performance and productivity of the girls affected but also the future generation as the cohort become mothers, since babies born from anemic mothers have a higher risk to suffer from anemia, low birth weight and stunting. ${ }^{4}$

The iron and folic acid supplementation program (IFAS) for adolescent girls and women in reproductive age has been started in 1997 in Indonesia. In 2016 the Ministry of Health (MoH) adapted the protocol to follow the WHO's 2011 guideline.(Roche 2018) The MoH protocol stated that the iron and folic acid supplement should be given weekly at school and should be supported by cross sector collaboration from the Ministry of Health $(\mathrm{MoH})$, Ministry of Education (MoE), 
Ministry of Religious Affairs (MoRA) and Ministry of Home Affairs (MoHA). The school based weekly iron and folic acid supplementation program was aimed to improve adherence as well as reducing the possible side effects without lowering the efficacy. ${ }^{5,6,7}$ However, the program has not meet its target with only $1.4 \%$ female adolescent consumed 52 tablets in a year. ${ }^{8}$

Previous research explored the issue of adherence to IFAS from individual perspective which focuses on knowledge, perceived benefit, perceived susceptibility, perceived seriousness, perceived threat, and perceived barriers. Findings suggest the barriers for the adherence due to lack of nutritional education, low tablet quality, no drinking water supply and lack of monitoring. ${ }^{9,10,11}$ They are limited information on the school community perspective on the program and their readiness to adopt ad support the implementation of the program. With the paucity of research using ecological perspective, this study utilized the social ecological model and the community readiness model to identify and analyze policies, program guidelines, stakeholders' perspective, school community knowledge as well as school community readiness to implement the school based weekly iron and folic acid supplementation (WIFAS)

Table 7 Document source and analysis result

\begin{tabular}{|l|l|}
\hline Document name & Source \\
\hline $\begin{array}{l}\text { Number of Girl student have } \\
\text { anemia risk according health } \\
\text { screening } \\
\text { Number of IFA distribution }\end{array}$ & $\begin{array}{l}\text { Health promotion } \\
\text { Health district office }\end{array}$ \\
\hline School list at Kota Depok & $\begin{array}{l}\text { Nutrition Division of } \\
\text { Health district Depok }\end{array}$ \\
\hline Report of IFA coverage per year & $\begin{array}{l}\text { Nutrition Division of } \\
\text { Health district Depok }\end{array}$ \\
\hline $\begin{array}{l}\text { Standard of procedure of IFA } \\
\text { distribution } \\
\text { IFA distribution monitoring form }\end{array}$ & Primary Health center \\
\hline
\end{tabular}

The qualitative data from respondents in the first stage as well as the school principals in second stage were gathered using in depth interview. Document review and direct observations were done as a mean of triangulation. Qualitative data were analyzed using thematic analysis ${ }^{12}$.Verbatim transcripts were all in Bahasa Indonesia, analysis was done in Bahasa Indonesia using an open code method in Microsoft excel where highlighted themes and quotes were then translated into English. Qualitative data is presented according to the rules of qualitative research in the form of quotations.

The second stage focused on the school as the program gatekeeper. We employed the Community Readiness Model (CRM) using the modified Community Readiness Tool (CRT) to analyze the school community which will help evaluate and improve adherence to WIFAS.

\section{METHODS}

\section{Formative and qualitative study method}

The study used mixed method design which consist of two sequential stage. The first stage was the formative study which aimed to identify supporting policies and guideline for program implementation. This stage also aimed to explore stakeholders' awareness of the program. The stakeholders were from the City Health Authority, the Regional Education Authority and the community health centers. The formative stage employed in depth interview to explore stakeholders' awareness and knowledge on the current WIFAS program and guidelines. The respondents for this stage were person in charge for nutrition program in the city health authority office, the regional education authority, nutrition staffs from 10 community health centers the total respondents for this stage was. Document analysis was done as triangulation of findings from interview. Document source and analysis result could be seen at Table 7 .

\section{Analysis result}

Primary Health Center list which have the most girl

student with anemia risk in Kota Depok, 2017

Number of IFA was provided and distributed as much as number of girl student from Dapodik and IFA stock is sufficient till end year.

School list at Kota Depok which take IFA program (60 senior high school and 84 junior high school)

IFA distribution coverage always enhances year by year

Flow chart of IFA distribution at school accomplished by $\mathrm{Hb}$ screening test and health education for student Only 2 school could show IFA distribution monitoring form readiness to implement the WIFAS program at school. The CRM explored 5 dimensions of the community readiness namely School Community Awareness about problem regarding adherence for WIFAS, School Community Climate toward adolescents girls' adherence problem, School Community knowledge of Effort to improve adherence for WIFAS, School Community Resources Availability to support WIFAS implementation at school and the last is the School Leadership Support to improve adherence to WIFAS. The research was done from August 2018 to March 2019 in Depok City, situated on the outskirt of Indonesian capital city of Jakarta.

The second stage was done at school level, the target schools were high schools which have received the WIFAS program. The schools were chosen purposively 
from list of 10 community health centers with the highest anemia prevalence based on the Depok Health District Office school student's health screening report on 2017 and 18 schools were chosen. This stage involves concurrent qualitative and quantitative data collection. The respondents for the in-depth interviews were 18 school principals or vice school principals while the quantitative study involved 115 respondents of school principals and teachers using questionnaire adapted from community readiness model as well as the Knowledge, Attitude and Practice (KAP) survey model.

The quantitative data presented in tables includes the school readiness score and the school community knowledge about anemia score, the school community's attitude toward WIFAS score and school community practice of WIFAS program score. Univariate analysis is presented in mean and standard deviation of school readiness score, school community of knowledge about anemia score, school community attitude toward WIFAS's score and school based WIFAS implementation program score. Bivariate data presented the correlation between independent variable (school characteristic, school community knowledge, school attitude, school readiness) with school based WIFAS implementation program score. While multivariate analysis presented regression analysis of weekly iron folic acid supplementation program implementation. Quantitative data analysis was done using the SPSS 23.IBM corporation.

All respondents were provided a brief explanation regarding the research, an assurance of confidentiality, and we acquired written, informed consent prior to interviews. Ethical approval for the study was obtained from the Health Research Ethic Committee UPNVJ, protocol number: B/1607/IX/2018/KEPK.

\section{RESULTS AND DISCUSSION}

\section{Formative Findings}

According to the social ecological model, key policy holders must be involved in behavior change in this case to increase the compliance of WIFAS among female students (see figure 1). Change agents such as parents, teachers, administrators, social activists, NonGovernment Organizations (NGOs), the Ministry of Health, the Ministry of Education, provincial and regional / city governments need to coordinate in action and influence behavior change at all levels. ${ }^{15}$ Therefore in this study we explored stakeholder's perspective of WIFAS program implementation. The respondent list could be seen in table 6.

Table 6 Respondent for Formative study

\begin{tabular}{|c|c|c|}
\hline Institution & Number of respondents & Position \\
\hline Health district office & 1 & $\begin{array}{l}\text { Head and staff of Nutrition and family } \\
\text { health division }\end{array}$ \\
\hline Education regional branch Office & 1 & Head of education provider service \\
\hline Primary health care & 8 & Nutrition staff \\
\hline Total & 10 & \\
\hline
\end{tabular}

Respondents from the health sectors in the City Health Authority office and the community health centers were well aware of the school based WIFAS program for female adolescent and stated that the program have been started in 2015. The health officials in the City Health Authority office stated correctly that the program was conducted based on several regulations 1) Presidential Regulation No. 42 of 2013 concerning the National Movement for the Acceleration of Nutrition Improvement which focuses on saving the first 1000 days of life, 2) Joint Regulation between the Minister of Education and Culture, Republic of Indonesia Minister of Health, Minister of Religion and Minister of Home Affairs Number 6 / X / PB // 2014; Number 73 of 2014, Number 41 of 2014; Number 81 of 2014 concerning Development of School / Madrasah Health unit; 3) Regulation of the Minister of Health No. 08 of 2014 concerning Iron Folic acid Supplementation program for Women of Childbearing Age and Pregnant Women and 4)
Directorate General of Public Health Circular No.HK/03.03/V/0595/2016 concerning Iron Folic acid Supplementation for Adolescent Girl. ${ }^{13}$

At the local level, the MoH Circular Letter was followed up by governor regulations. In West Java province, West Java Governor issued the Circular No. 440 / 25 / Yanbangsos concerning Policy Support for Iron Folic Acid Supplementation Program for Adolescent Girl and Women in childbearing age. ${ }^{14}$ In addition to the governor circular, the regional education office had followed up by issuing the Letter of Notification Number:421.7/309.cadisdik.Wil.Il/2018 to senior high school principals under their jurisdiction. Notifying the role of schools to be responsible for conducting the WIFAS at school at an arranged day every week, distributing the supplement to their female students as well as recording the students' adherence in the adherence monitoring card. 


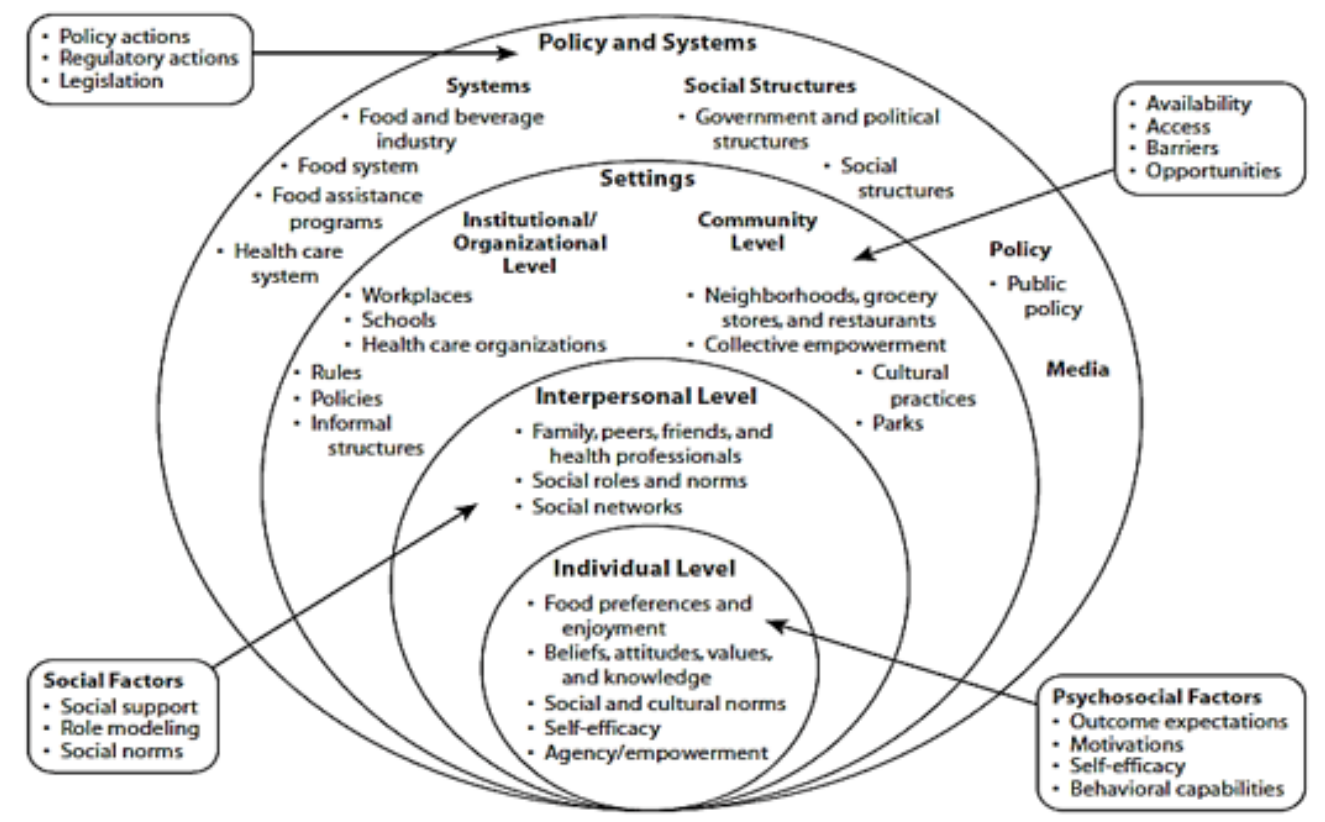

Figure 1.

Social ecological model: Approaches at different levels of action

The interview with health sectors also highlights that the coverage of the program has been increasing overtime, with the current coverage in the city of Depok is $23.8 \%$ which is close to the national target of the $\mathrm{MoH}$ strategic plan of 2015-2019 which is $30 \%$. The program implementation was also done according to guideline where socialization is conducted to schools before the program started and if resources are adequate a hemoglobin check is conducted.

" Our haemoglobin screening among school going adolescent girl in Depok found that the prevalence of anemia was $20.9 \%$. The program has been around for three years, this year we aimed to increase our coverage to meet the national target of $30 \%$ based on the ministry of health's strategic plan. In April 2018 we made a cross sector commitment between the City Health Authority and the Education Authority, Religious Affairs Office, the City Women Empowerment and Child Protection Authority as well as the local Women Organizations." (Head Staff on Family Nutrition, City Health Authority Office)

However, on the other side of the coin despite the official support in the form of notification letters issued by the regional education authority office the education sector seems to be less engaged in the issue. This may due to lack of monitoring and evaluation from the education office because a prominent belief that the health sector should be the leading sector and being supportive of the program is mainly translated as not becoming a barrier for the health sectors to do whatever they need to do to implement the program.

"This is a health program so certainly the leading sector is the health authorities; the regional education office will support and facilitates. The health office has the program, education regional office has the participants or the students we don't prevent students from taking the supplement and we notify schools to help the health sector. (Head Section of Education Regional Branch Office)

In the field the community health centers (Puskesmas) as the spearhead for the program implementation often having difficulties in conducting awareness campaign about the WIFAS, Coordination with schools are often time consuming and met with resistance but not only for WIFAS program but the schoolbased health program in general. Not all schools are welcoming and not all schools have the staffs (teachers responsible for the school health program) nor the resources (drinking water, health care room) to sufficiently conduct the program.

"We, the Primary Health Center often invite School health teachers in various awareness campaign for Primary health center programs such as Immunization program both for the routine and outbreak response including the iron supplementation. However, there are still obstacles, not all school teachers are welcome, and there are no school health teachers, so there is no coordination with schools. (Head sub unit of family health division of Health district 
office and Nutrition Staff of community health Center)

"not all schools are willing and able to work together with Puskesmas in the sense that they are willing to run a sustainable health program, many schools also refused" (Nutrition Staff of Primary Community Health Center).

In Indonesia, The Community Health Center often involve the schools in the implementation of health programs such as vaccination program and the provision of vitamin A. But the school's response to health programs varies. There are schools that are willing to cooperate, some are not. These variations can be caused by several factors including the knowledge and attitudes of leaders and school teachers, school readiness factors and the adequacy of support from the health office and the education office. The attitude of school teachers to health is a reflection of their knowledge and perceptions of health. As the spearhead of education and as role models (role models) the attitudes of the teachers will be reflected in the health behavior of their students. ${ }^{19}$

Table 1. High School Characteristic and WIFAS implementation

\begin{tabular}{lll}
\hline Respondents' High-School Characteristic and WIFAS implementation & $\mathrm{n}^{*}$ & $\%$ \\
\hline School Status & 8 & 44.4 \\
- General High School (Public and Private) & 9 & 50.0 \\
-Private Vocational High School & 1 & 5.6 \\
-Private Islamic High School & 11 & 61.1 \\
School community had ever received WIFAS socialization from PHC staff & 7 & 38.9 \\
School community conducting drinking IFAS together at school per week & 9 & 50.0 \\
School community monitored adolescent girls' adherence & 5 & 27.8 \\
School documenting adolescent girls' adherence to WIFAS &
\end{tabular}

$\mathrm{n}^{*}=18 \mathrm{High}$ school consist of 155 teacher and headmaster.

The study found $61.1 \%$ of all senior high schools chosen as sample in this study received awareness campaign regarding the school based WIFAS program from the city health authority or the community health center. However only $38,9 \%$ have conducted a drinking together session once a week while only $27,8 \%$ schools that recorded their students' adherence (Table 1). In depth interviews with the school principals highlighted the common reasons for not conducting the drinking together were: 1) did not receive any awareness campaign from the health sector, 2) did not know or receive the notification letter from the regional education authority thus did not understand their role and responsibility regarding the program, 3 ) did receive the notification letter but do not have sufficient resources (man, time and place) to conduct the weekly event, 4) the school community did not perceive that anemia is a problem for their student, 5) the school have tried to conduct drinking together but many female students refuse to take the supplement in fear of possible side effects and the last one was rejection from parents thus the school could not impose the program to their students. In line to the perceptive from the regional education authority, the school also perceived that they are basically inept to push this program forward and the fact that the policy support from the regional office is only in the form of notification letter did not help.

"In my opinion, the circular notification letter from the regional office is normative so there is no obligation, because the students felt nauseous when they took the tablet, the taste is also not good and there are parents who voiced their rejection that their daughter has to take the tablet there are fears for side effects and we could not do anything about that" (Principals, Public Senior High School $\mathrm{XX})$

Utilization of IFAS can be influenced at individual and structural environmental level. ${ }^{16}$ Among the barrier for compliance was disrupted supply of the IFA tablet 17,18 . However, in the case of Depok City, the City Health Authority has provided enough IFAS and through the community health centers the IFAS were distributed to the target schools. The community health centers also responsible for conducting the awareness campaign. In this program scenario, the school community is the point for the IFAS distribution. However, many schools that did not conduct weekly event to take the IFAS, did not monitor nor record adherence to students consuming the IFAS as stated in the guideline. Priya et al. found three broad categories of barriers for IFA consumption among students. First broad category of factors responsible for barrier of IFA consisted of stomachache and nausea, metallic taste, disliking, and giddiness. The second group consisted of fear of side effects of IFA tablets and thinking of IFA was not necessary. The third group consisted lack of awareness and peer influence on not consuming tablets. ${ }^{19}$ Behavioral change strategy should focus on providing a supportive environment through awareness campaign and peer support to inform and help students to manage fear for side effects as well as the actual side effect, if they experience it.

Quantitative Findings

The quantitative findings found the average score of the school community on knowledge regarding anemia was low with the score of 54.52 (SD \pm 15.36 ) from the ideal score of 100 (see Table 2). The lowest score were 
for knowledge on fact that iron and folic acid supplement should be given weekly all year round where only $5.6 \%$ respondents were able to answer correctly that iron and folic acid supplement is given once weekly all year around, $6.7 \%$ were able to answer correctly the side effect of WIFAS, $5.6 \%$ respondents were able to mention illness related to anemia and only $16.6 \%$ were able to identify the sign and symptoms for anemia.

Table 2. Score of school Community's Knowledge, attitude and practice toward anemia and IFAS implementation ( $n=18$ High school consist of 155 teacher and headmaster)

\begin{tabular}{llll}
\hline Measures & Mean \pm SD & Min & Max \\
\hline School community knowledge score about anemia & $11.09 \pm 1.94$ & 7.20 & 16.00 \\
School community attitude score about WIFAS & $33.27 \pm 4.07$ & 27.60 & 40.00 \\
implementation & & & \\
Health Office District's support score & $1.41 \pm 0.46$ & 0.87 & 2.00 \\
Education Regional Office's support score & $0.57 \pm 0.61$ & 0.00 & 2.00 \\
School community practice score on WIFAS implementation & $1.56 \pm 1.33$ & 0.00 & 4.00 \\
\hline
\end{tabular}

The knowledge of the school community (teachers and principals) about anemia in adolescent girls is still limited, this is in line with research from Al Nasir (2004) in Bahrain which states the majority of teacher knowledge about health such as anemia, HIV, asthma, diabetes mellitus, smoking is still limited. This can affect the attitudes and behavior of teachers towards student health problems, even though the teacher is a role model (role modeling) for students. ${ }^{19}$ In India, the school community awareness about anemia was good but WIFS implementation in schools was still not regular. ${ }^{20}$ Thus knowledge alone may not be sufficient. There is a need to strengthen the program by giving proper training to the teachers and by giving health education to the parents and students about the benefits of WIFAS. ${ }^{11}$

The school communities' attitude toward WIFAS program was generally good with the average score of 83.41 (SD \pm 15.45 ) from the ideal score of 100 . The respondents mostly agreed on the statement that schools should educate parents about IFA's benefit (100\%), teacher should provide counselling to students about the benefit IFA (94.4\%), schools have a vital role to prevent anemia in adolescent girl (94.4\%), school have to involve student's peer or organization to improve adherence to consume IFAS (4.4\%).

The attitude of the school teachers in this study was mostly quite good, but there were some negative attitudes including disagreeing if the teacher needed to provide material for the benefits of the IFAS in their teaching $(22.4 \%)$, the teacher needed to collaborate with other sectors in an effort to increase compliance with WIFAS amongst students (22.3\%), schools need to monitor the compliance of students in schools (16.8\%) and teachers need to provide examples of drinking the IFAS once a week (16.7\%). This was also found in the 2014 Kheirouri and Alizadeh study which found $32.8 \%$ of teachers stated that WIFAS distribution in schools disrupted the learning process and were not willing to drink IFAS in schools as role models for students. ${ }^{21}$ Patimah (2019) states that building teacher performance must be with emotional intelligence, motivation and leadership that will become part of the school culture. ${ }^{13}$ Maslowski (2002) which cited by MacNeil (2009) also states that school functions can be influenced by basic assumptions, adopted norms and values, as well as a culture that is distributed to school members. ${ }^{14}$

Table 3 School Readiness Dimension Score to Support Adolescent Girls' adherence for IFAS ( $n=18$ High school consist of 155 teacher and headmaster)

\begin{tabular}{|c|c|c|c|}
\hline School Readiness Dimension & Mean \pm SD & Min & Max \\
\hline School Community Awareness about problem regarding adherence for WIFAS & $4.21 \pm 0.90$ & 3.00 & 6.00 \\
\hline \multicolumn{4}{|l|}{ School Community Climate toward adolescents' girl adherence problem in consume } \\
\hline WIFAS & $3.16 \pm 1.05$ & 1.80 & 5.20 \\
\hline \multicolumn{4}{|l|}{ School Community knowledge of Effort to improve adherence for WIFAS } \\
\hline School Community Resources Availability to support WIFAS implementation at school & $2.41 \pm 1.01$ & 1.00 & 4.00 \\
\hline \multirow[t]{2}{*}{ School Leadership Support to improve adherence to WIFAS } & $2.87 \pm 1.05$ & 1.00 & 4.00 \\
\hline & $4.28 \pm 1.33$ & 2.00 & 6.50 \\
\hline School Readiness total score & $3.36 \pm 0.82$ & 1.93 & 4.90 \\
\hline
\end{tabular}

The majority of schools (55.6\%) have not implemented the WIFAS program according to the 2016 $\mathrm{MoH}$ guidelines. The average score for implementation was 36.96 ( $S D \pm 1.33$ ) from the ideal score of 100 . As many as $61.1 \%$ of schools perceived that the supports given by the City Health Authority and the Regional Education Authority were inadequate but somewhat higher for the health authority. The average score for the support from the health authority and the education authority were $0.57(\mathrm{SD} \pm 0.61)$ and $1.41( \pm 0.46)$ respectively. 
The bivariate analysis found a linear correlation between the score of supports from the City Health Authority and the total score of the school community readiness with implementation of WIFAS at school ( $r=0.6$ and $r=0.7, p$ value $<0.005)$. Multivariate regression analysis found that the strongest correlation with implementation of WIFAS at school was the school readiness total score, $r=0.933, p$ value $=0.000$ with supports from the city health authority as a considerable covariant (Table 4 and 5).

Table 4 Correlation between Independent variable with dependent variable

\begin{tabular}{llll}
\hline Variable & $r$ & R2 & Pvalue \\
\hline School community knowledge score about anemia & 0.413 & 0.171 & 0.088 \\
School community attitude score about WIFAS implementation & 0.295 & 0.087 & 0.234 \\
School had ever received WIFAS socialization from primary health care center staff & 0.416 & 0.173 & 0.086 \\
Health Office District's support score & 0.681 & 0.464 & 0.002 \\
Education Regional Office's support score & 0.229 & 0.052 & 0.361 \\
School Readiness total score & 0.771 & 0.594 & 0.000 \\
\hline
\end{tabular}

Schools must be a gateway to the promotion of health for the entire community. In 1997 the WHO initiated the Global School Health initiative "The Health Promoting School" which focused on school-based health improvement activities. This effort needs to strengthen the capacity of schools as a healthy place to live, study and work. ${ }^{15}$ The school readiness model is an important community and environmental factor that contributes to behavior change. ${ }^{16}$ The average score for the school community readiness in this study was found 3.36 (SD \pm 0.82 ) from the ideal score of 9 , the score showed that the school community readiness for WIFAS implementation was in the vague awareness stage. At this stage the school has the characteristics of no motivation to act immediately, vague knowledge about adolescent girls' adherence to drinking WIFAS and limited resources to deal with problems, the school realizes that the problem of compliance with drinking IFAS is a problem that must be resolved but does not know how and assume other parties outside the school can solve the problem. ${ }^{17}$ The lack of readiness from the school community to support and monitor WIFAS program in their respective schools can be considered as a structural barrier to adherence. The latest Riskesdas found that the top three main reasons for WIFAS noncompliance were unfelt need of the supplement (26.1\%), dislike of the taste and odor $(22.9 \%)$ and forgetfulness (20\%) dislike of the taste and odor ${ }^{8}$. A study in India also found that informational was the fundamental factor behind low adherence to IFA consumption. Thus, on a policy perspective, all the attempts should be done to instigate arise felt need' among target groups for IFA consumption including through the school community 22

Table 5 Regression linier model for WIFAS implementation

\begin{tabular}{lllll}
\hline Model parameters & $\mathrm{R}$ & $\mathrm{R}$ square & Beta Coefficient & $\mathrm{P}$ \\
\hline Constant & 0.797 & 0.635 & 2.723 & 0.000 \\
School readiness to implement WIFAS & & & 0.933 & 0.018 \\
Health Office district support score & & & 0.816 & 0.217 \\
\hline
\end{tabular}

The community members had limited knowledge on WIFAS program and adherence with the WIFAS. However, the community leader in case are the school principals and some community member belief that there is problem of anemia problem in the school and the adherence to WIFAS was low but not yet motivated to take an action to solve the problem due to perceived limitation in resources. The school awareness dimension of the problem of low adherence to drinking students and leadership has the highest score of 4 (pre planning stage) which means schools and school leadership are aware of the problem of low compliance with WIFAS among students and the need to increase adherence but lack of knowledge and guidance on how to do it. The dimension that has the lowest score is the knowledge dimension of effort and resource dimensions (2.41 and 2.87). According to CRM, these two dimensions are in the second stage (resistance / reject stage). The average school does not yet know that there is an effort that can be made to improve the adherence of students drinking IFAS, including taking IFAS together, monitoring and recording the compliance of students drinking IFAS regularly.

The stage of school readiness can be improved through intervention efforts that are adjusted to the stage of readiness that has been achieved. Intervention efforts that can be done include increasing school knowledge, motivation and capacity. Several studies have examined several efforts that can be made to improve the stages of community readiness. ${ }^{23,} 24,25$ These intervention efforts can be implemented through training and providing supporting resources. Provision of training and supportive supervision for teachers and students peer educator on how to counsel adolescent girls on benefits, side-effects, and when, why, and how to take IFA supplements should be part of the behavior change communication.

The strength of this study is this is the first study in Indonesia to map out the school community readiness for school based weekly iron folic acid supplementation 
program. The study also provides insight on the stage of the school readiness and the type of supports needed based on the qualitative and quantitative data. This study also already involves public school, private school, and religion school which could gain heterogeneity perspective. This study using Community readiness model (CRM ) which has ability to provide intervention strategies tailored to the community's level of readiness, and provided key contextual information which improved intervention development or evaluation ${ }^{26}$.

The current study also has several limitations that warrant discussion, there were a perceived lack of rigor in the development of the tool and its dependency on key informant perspectives. Kostadinov (2015) reported that limitations of the community readiness tool were the issue of subjective scoring, in which qualitative interview results are scored by researchers on an anchored rating scale rather than captured through the use of an objective standard. ${ }^{27}$ Other limitations included: response bias by the key informants; the ever changing and transient nature of readiness not being suited to measurement at a single point in time.

\section{CONCLUSION}

School-based WIFAS program aimed to decrease anemia and improve female adolescent's adherence to consume IFAS. Policies and program guideline were already established since 2016. However, there's still gap between program guideline, stakeholder's perspectives and school-based WIFAS program implementation. School readiness model is important factor of community and environment which contribute to behavior change. School readiness in Depok City at vague awareness stage to implement WIFAS program. School realize that anemia and schoolgirl adherence to consume WIFAS had to solve but did not know how and assume outside parties can help solve the problem. In this case the support of the City Health Authority and Education Regional Office is expected to help improve the readiness of school to adopt and implement school based WIFAS program.

\section{ACKNOWLEDGEMENT}

The author would like to express their sincere gratitude to the Health District Office of Kota Depok and Education Branch Regional Office II Bogor, West Java Province for permiting the study.

\section{REFERENCE}

1. World Health Organization. the Global Prevalence of Anaemia in 2011. WHO Rep. 48 (2011) doi:10.1017/S1368980008002401.

2. Health Research and Development Body, H. M. R. I. Laporan Riset Kesehatan Dasar. Kementerian Kesehatan Republik Indonesia (2013) .1 Desember 2013.
3. Kementrian Kesehatan RI. Kementerian Kesehatan Republik Indonesia. Rencana Strategis Kementerian Kesehatan Tahun Rencana Strategis Kementerian Kesehatan Tahun 2015-2019. (2015). doi:351.077 Ind r.

4. Ahmed, T., Hossain, M., Istiaque, K. \& Asia, S. Global Burden of Maternal and Child Undernutrition and Micronutrient Deficiencies. Ann Nutr. Metab. 61, 8-17 (2013).

5. Briawan, D. Efikasi Suplemen Besi-Multivitamin Untuk Perbaikan Status Besi Remaja Wanita. (Institut Pertanian Bogor 2008).

6. Vir, S. C., Singh, N., Nigam, A. K. \& Jain, R. Weekly iron and folic acid supplementation with counseling reduces anemia in adolescent girls: A large-scale effectiveness study in Uttar Pradesh, India. Food Nutr. Bull. 1, 186-194 (2008).

7. Joshi, M. \& Gumashta, R. Weekly Iron Folate Supplementation in Adolescent Girls - An Effective Nutritional Measure for the Management of Iron Deficiency Anaemia. Glob. J. Health Sci. 5, 188-194 (2013).

8. Kementerian Kesehatan RI Badan Penelitian dan Pengembangan Kesehatan. Laporan Nasional RISKESDAS 2018. (2019).

9. Bhatt, R. J. A study of access and compliance of iron and folic acid tablets for prevention and cure of anaemia among adolescent age group females in Ahmedabad district of India surveyed under multi indicator cluster survey. Glob. J. Med. Public Heal. 2, 2-6 (2013).

10. Aprianti Riri, S. M. G. and K. T. Factors Correlated With The Intention of Iron Tablet Consumption among Female Adolescent. J. Ners 13, 122-127 (2018).

11. Apriani Mirza, Ahmas Syafiq. Adolescent Compliance on Iron Tablet Consumption: A Systematic Review. Adv. Sci. Lett. 24, 63716375 (2018).

12. Creswell, J. W. Research Design: Qualitative, Quantitative, and Mixed Methods Approaches. Research design Qualitative quantitative and mixed methods approaches (2013). doi:10.1007/s13398-014-0173-7.2.

13. Chaleunsouk, L. The School Food and Beverage Policy: Examining Schools' Readiness to Implement the Policy With Organizational Readiness for Change. Analysis 170 (2012).

14. Kementerian Kesehatan Republik Indonesia. Pedoman pencegahan dan penanggulanngan anemia pada Remaja Putri dan Wanita Usia Subur. 14 (2016).

15. Gubernur Jawa Barat. SURAT EDARAN GUBERNUR JAWA BARAT. NO. 440/25/Yanbangsos Tentang Dukungan Kebijakan Pemberian Tablet Tambah Darah pada Remaja Putri dan Wanita Usia Subur.23 Maret 2018. (2018).

16. Alnasir, F. A. Health attitudes of school teachers. Saudi Med. J. 25, 326-330 (2004).

17. Tinago, C. B., Annang Ingram, L., Blake, C. E. \& Frongillo, E. A. Individual and structural 
environmental influences on utilization of iron and folic acid supplementation among pregnant women in Harare, Zimbabwe. Matern. Child Nutr. 13, 1-11 (2017).

18. Kavle, J. A. \& Landry, M. Community-based distribution of iron-folic acid supplementation in low- and middle-income countries: A review of evidence and programme implications. Public Health Nutr. 21, 346-354 (2018).

19. Priya, Sh. et al. Factors influencing weekly iron folic acid supplementation programme among school children: Where to focus our attention? Saudi J. Heal. Sci. 5, 28 (2016).

20. Sharada AK. \& Thilak, SA.. Evaluation of Weekly Iron and Folic Acid Supplementation Programme for adolescents in rural schools of Kannur, North Kerala, India: A cross-sectional study. Int. J. Med. Sci. Public Heal. 5, 2259 (2016).

21. Kheirouri, S. \& Alizadeh, M. Process evaluation of a national school-based iron supplementation program for adolescent girls in Iran. BMC Public Health 14, 959 (2014).

22. Bali, S. et al. How non consumers differ from consumers: A qualitative approach to synthesise the attributes of iron folic acid end users. J. Clin. Diagnostic Res. 11, LC18-LC22 (2017).
23. Fagan, A. A., Hanson, K., Hawkins, J. D. \& Arthur, M. W. Implementing effective communitybased prevention programs in the community youth development study. Youth Violence Juv. Justice (2008) doi:10.1177/1541204008315937.

24. Åhström, M., Larsson, N. \& Lindberg, L. Change of Community Readiness Over Time: Measurements of Reduction of Parental Support and Availability of Alcohol in Seven Communities. Health Promot. Pract. 17, 586595 (2016).

25. Nykiforuk, C. \& N. L. Idea Readiness Tool:Understanding a School Community's Readiness for Adopting a New Idea and Strategies for Taking Action. (School of Public Health, University of ALberta, 2016).

26. Kostadinov, I., Daniel, M., Stanley, L., Gancia, A. \& Cargo, M. A systematic review of community readiness tool applications: Implications for reporting. International Journal of Environmental Research and Public Health vol. 12 (2015).

27. Kostadinov, l., Daniel, M., Stanley, L. \& Cargo, $M$. Assessing community readiness online: $A$ concurrent validation study. BMC Public Health 15, 1-6 (2015). 